ORIGINAL PAPER

\title{
LiMiTED USEFULNESS OF HISTOPATHOLOGICAL FEATURES IN IDENTIFICATION OF A CLINICALLY AGGRESSIVE SOLID- PSEUDOPAPILLARY NEOPLASM OF THE PANCREAS
}

\author{
Łukasz Liszka ${ }^{1}$, SŁawomir Mrowiec ${ }^{2}$, Jacek Pają ${ }^{1}$, Anna Kostrząb-Zdebel ${ }^{1}$, Pawee Lampe ${ }^{2}$,
} MACIEJ KAJOR ${ }^{1}$

${ }^{1}$ Department of Pathomorphology in Katowice, Medical University of Silesia, Katowice, Poland

${ }^{2}$ Department of Gastrointestinal Surgery, Medical University of Silesia, Katowice, Poland

\begin{abstract}
Solid-pseudopapillary neoplasms (SPN) are rare tumours of the pancreas. Distant metastases and/or local recurrence following surgical resection occur in $10 \%$ to $15 \%$ of patients with SPN. In the present study, we aimed to systematically examine the usefulness of virtually all histopathological features of SPN which were previously considered potential risk factors of clinically aggressive behaviour of SPN following surgical resection. Seventeen SPN were included. None of the cases had an undifferentiated component. Follow-up data were available for 14 patients (median 52 months). One patient developed liver metastasis 17 months after resection of the primary tumour and fulfilled the criteria of a clinically aggressive disease. None of the histopathological features allowed identification of that case with an adequate diagnostic yield. At present, histopathological examination cannot identify patients who may develop tumour recurrence following resection of the primary lesion. A close follow-up should be offered to all patients treated for SPN.
\end{abstract}

Key words: solid pseudopapillary neoplasm, pancreatic neoplasms, pancreas.

\section{Introduction}

Solid-pseudopapillary neoplasms (SPN) are tumours of the pancreas of a peculiar histopathology and of a still uncovered cellular origin [1-4]. SPN constitute from less than $1 \%$ up to $6 \%$ of all pancreatic tumours [5-7], and from less than $5 \%$ up to $20 \%$ of cystic pancreatic tumours $[6,8]$. The SPN occur usually but not exclusively in young females and only in a minor portion of cases behave in a clinically aggressive/ malignant manner. Distant metastases and/or local recurrence following surgical resection occur in $10 \%$ to $15 \%$ of patients with SPN. Despite this, long-term survival can be achieved in many patients with metastatic and/or unresectable disease [9, 10]. CTNNB1 ( $\beta$-catenin) mutation is a very typical feature of SPN at the genomic level [11] and the only repetitive mu- tation in samples of SPN examined using whole-exome sequencing [12]. SPN was reported as a diagnostic entity in 1959 by Frantz [13], and Hamoudi et al. were the first who report ultrastructural features of SPN in 1970 [14]. The diagnostic category of solid-pseudopapillary carcinoma (SPC), defined based on presence of angioinvasion, perineural invasion, deep invasion into the surrounding tissues, and/or metastasis was included in the WHO reference book in 1996 [8] and in 2000 [15]. Despite significant efforts to find clinical, histopathological, or molecular features which would be useful as prognostic factors for patients with SPN, results of available reports are not fully satisfactory (as reviewed in [16-21]).

In the present study, we aimed to systematically examine the usefulness of virtually all histopathological features of SPN which were previously considered 
potential risk factors of a clinically aggressive behavior of SPN following surgical resection.

\section{Material and methods}

\section{Literature search}

The PubMed database was searched (last search in March 2014) for studies on SPN describing clinical and histopathological features which may serve as prognostic factors for patients with SPN. Key words used were: "solid or pseudopapillary or solid-pseudopapillary or papillary-cystic or solid-cystic or papillary or cystic or Frantz or Frantz's or Hamoudi or Hamoudi's" and "pancreas or pancreatic". To identify studies on aggressive SPN, key words used were: "aggressive or aggressiveness or recurrent or recurrence or metastasis or metastases or metastatic or invasive or unresectable or non-resectable or death or died or mortality".

\section{Study cases}

SPN were identified in the institutional database of pancreatic specimens established in 1985. Cases between 2007 and 2013 were gathered prospectively, while cases prior to that period were found retrospectively based on re-evaluation of specimens irrespective of primary diagnoses. This allowed identification of SPN that could have been misdiagnosed as tumours of neuroendocrine differentiation in early years [22].

Aggressive behavior was defined as development of recurrence and/or metastasis during the follow-up period after surgical resection [5]. Follow-up data were gathered by telephone or personal interviews of the patients or their family members.

The diagnoses were established using reference sources $[1,2]$. Hematoxylin-eosin slides were re-assessed for histopathological features potentially useful in predicting the aggressive behaviour of SPN, as detailed in the 'Results' section.

\section{Tissue microarray}

Tissue microarray (TMA) [23] was prepared using a manual instrument (MTA-1, Beecher Instruments, Sun Prairie, WI, USA). Four cores (diameter $1.5 \mathrm{~mm}$ ) were taken from each case.

\section{Immunohistochemical stains and their interpretation}

Immunohistochemical (IHC) stains were performed using TMA slides, with the exception of a single recent case which was examined using conventional sections. IHC stains useful in diagnosis of SPN ( $\beta$-catenin, CD10, CD56, progesterone receptor (PgR), synaptophysin, p53, Ki-67, claudin-5) were performed [22, 24-26]. Details on IHC protocols are described in Supplementary Table I. In brief, 4-mi- crometer thick sections were cut from TMA block and put onto Superfrost Plus slides (Menzel-Glaser, Braunschweig, Germany). Heat-induced antigen retrieval was performed using PT Link module (Dako, Glostrup, Denmark) or a water bath, and incubation in $3 \% \mathrm{H}_{2} \mathrm{O}_{2}$ served as a peroxidase block. Diaminobenzidine and hematoxylin were used as a chromogen and a counterstain, respectively. For the negative control, primary antibodies were omitted. An automated IHC machine (Dako) was used for IHC assays.

The $\beta$-catenin stain was considered 'positive' if tumour cells showed nuclear and cytoplasmic staining, an indicator of activation of Wnt signalling pathway $[27,28]$. The $p 53$ stain was recognized as 'positive' if more than $30 \%$ of nuclei showed strong nuclear staining [29]. For CD10, CD56, synaptophysin and claudin- 5 stains, stain intensity (0-none, $1+$ weak, $2+$ moderate, $3+$ strong) and stain extent (as a percentage) was recorded. Histoscores were obtained by multiplying the particular values of intensity and values of stain extent and adding the products received for each stain score (histoscore range: 0-300) [30]. For $\mathrm{PgR}$ and $\mathrm{Ki}-67$ stains, the stain extent was expressed as a in percentage but the stain intensity was not taken into account (histoscore range: 0-100).

\section{Statistical analysis}

Mann-Whitney U tests and Spearman's rank correlation coefficient were calculated using Statistica 10 software (StatSoft, Tulsa, USA). A heatmap was drawn with Gene-E software [31].

\section{Ethics}

The institutional Review Board allowed the study to be performed without a detailed protocol appropriate for interventional studies involving human subjects.

\section{Results}

\section{Literature search}

The literature search revealed that at least 10 clinical and at least 35 histopathological features were considered potential prognostic factors and/or risk factors of aggressive behavior of SPN. The clinical factors included: male gender [5, 18, 32], patient's age $[5,18,32-34]$, body mass index [18], serum tumour markers [18, 33], presence of symptoms [18, $32]$, mean duration of symptoms [18, 32], non-resectability [35], extent of surgery [5, 36], familial occurrence of tumour [37], and multiple primary lesions in a single patient $[38,39]$. Histopathological factors included: extrapancreatic localization of the main neoplastic mass $[40,41]$, localization of tumour within particular segment of the pancreas [5, 18, 32], tumour diameter [5, 32, 42], gross characteristics of 
tumour (solid, cystic, or mixed) $[18,32,43]$, tumour rupture [43-45], lack of a tumour capsule [46] and incomplete capsule [47], capsule invasion [17, 18, 33, $48]$, invasion into pancreatic parenchyma $[17,33,49]$ or adjacent tissues or organs (invasion of duodenum, spleen, common bile duct, peripancreatic fat) $[17,18$, $33,44,501$, portal vein invasion with tumour thrombus [51], lymph node metastasis or distant metastasis at presentation and/or during resection of primary tumour $[17,33,49,50,52-55]$, presence of tumour tissue at surgical margin $[5,46,52,54,56]$, perineural invasion [5, 18], small vessels/lymphatic vessels invasion $[5,10,52]$, muscular vessel invasion $[5,49,57]$, diffuse growth pattern $[33,58,59]$, calcifications, including "marginally calcified totally necrotic" tumour picture $[18,32,43,60]$, tumour necrosis, either infarct-type or geographical [18, 33, 49], necrobiotic nests $[39,49,57,61]$, nuclear features (e.g. size, chromatin pattern, nucleoli, atypia) $[44,49,62,63]$, with particular emphasis on nuclear pleomorphism $[7,10$, $17,18,33,46,49,52]$ and presence of multinucleated tumour giant cells $[7,25,64]$, nuclear grade $[49$, 62], presence of features diagnostic of SPC, as defined using WHO 2000 criteria $[18,19,32,42,43,53$, 60, 65-68], presence of undifferentiated component [33], mitotic count [33, 49, 52], tumour grade and stage according to the 2006 European Neuroendocrine Tumor Society (ENETS) classification for neuroendocrine neoplasms of the pancreas, and tumour stage according to the 2010 American Joint Committee on Cancer (AJCC) TNM7 classification [5]. Additionally, Nishihara et al. developed a histopathology-based scoring scheme potentially useful in differentiation of metastatic and non-metastatic SPN [49]. It included assessment of nuclear grade, mitotic rate, cellular pleomorphism, venous invasion, necrobiotic nests, and necrosis [49]. Some nuclear morphometric features may also be useful for prediction of clinical aggressiveness of SPN as well [69]. Some researchers tested IHC stains as potential predictors of aggressive behavior: CD10, CD56, PgR, synaptophysin, p53, Ki-67, $\alpha 1$-antitrypsin, $\alpha 1$-antichymotrypsin, neuron-specific enolase, galectin-3, vimentin, chromogranin, pan-cytokeratin, Cam5.2, and epithelial membrane antigen (EMA) [11, 24, 32, 33, 70, 71].

The number of patients included in many series did not allow formal documentation of statistical significance $(\mathrm{p}<0.05)$ of particular features as predictors of aggressive behavior of SPN. This was possible only for male gender [72], tumour size [5, 35, 73], muscular vessel invasion [5], and ENETS primary tumour stage [5]. The association between male gender and clinical aggressiveness of SPN was seen in one [74], but not another [75] meta-synthetic study based on accumulative analysis of literature data.

Importantly, in patients with SPN, many potentially prognostic clinical and pathological features may be seen in patients with a clinically benign disease [5, 9, 32, 33, 46]. Moreover, clinically aggressive behavior may be observed in some patients without the clinico-pathological risk factors listed above $[11,33,46]$.

\section{Demographic data}

Eighteen cases of SPN were identified. A single case of SPN in a child diagnosed in incisional biopsy was excluded. The study population included 17 cases diagnosed in adult patients in resection specimens.

\section{TMA}

Thirteen cases were included in TMA block. In a single case, core biopsy of tumour tissue was not successful and that case was excluded from IHC TMA evaluation. A single case was represented in TMA by separate core biopsies of primary tumour and liver metastasis, as described below.

\section{Clinical features}

Clinico-pathological data are presented in Table I and Supplementary Fig. 1 (a heatmap). In all cases, the tumour was considered potentially resectable. Seven patients were treated with pancreaticoduodenectomy, and in 6 cases distal pancreatectomy was performed. Four tumours were enucleated. All cases were solitary.

\section{Macroscopic features}

All cases of SPN originated in the pancreas. In one early case from outside surgical centre the exact localization of the tumour within the pancreas was not known. Diameter of tumours did not correlate with patients' age (Spearman's rank correlation coefficient, $\mathrm{p}=0.325)$. Three cystic lesions were consistent with "marginally calcified partially necrotic" SPN [60]. Tumour rupture was not documented in any case. Gross pictures of some SPN are presented in Supplementary Fig. 2.

\section{Microscopic features}

All the histopathological features (excluding morphometric measurements) previously recognized as potential indicators of clinically aggressive diseases and enumerated above in the 'Literature search' section were examined in the study cases. In particular: (a) tumour at surgical margin was documented in cases when neoplastic cells reached inked margin in perpendicular section or were seen in en face section; (b) muscular vessel invasion was recognized when neoplastic cells were found within vascular spaces with circumferential layer of smooth muscle cells [5]; (c) diffuse growth pattern was defined as solid growth pattern with little stroma [33]; (d) necrobiotic nests were defined as clusters of cells with eosinophilic cytoplasm and pyknotic nuclei [25, 49]; (e) nucle- 
Table I. Clinico-pathological characteristics of the study cases ${ }^{a}$

\begin{tabular}{|c|c|c|c|}
\hline CHARACTERISTICS & Prevalence $(\mathrm{N}=17)$ & SENSITIVITY $^{\mathrm{b}}$ & SPECIFICITY ${ }^{\mathrm{b}}$ \\
\hline Male gender & $2 / 17(11.8 \%)$ & $0 / 1$ & $14 / 16(87.5 \%)$ \\
\hline Age (years) & $\begin{array}{c}\text { Median } 36 \\
\text { (range: } 22-69)\end{array}$ & - & - \\
\hline Age (years) - median or more & $10 / 17(58.8 \%)$ & $1 / 1$ & $7 / 16(43.75 \%)$ \\
\hline Enucleation versus partial pancreatectomy & $4: 13$ & $0 / 1$ & $12 / 16(75 \%)$ \\
\hline Tumour localization (head : body : tail : not known) ${ }^{c}$ & $8: 1: 7: 1$ & $0 / 1$ & $7 / 15(46.7 \%)$ \\
\hline Tumour diameter $(\mathrm{cm})$ & $\begin{array}{c}\text { Median } 7.8 \mathrm{~cm} \\
\text { (range: } 1.4-16 \mathrm{~cm})\end{array}$ & - & - \\
\hline Tumour diameter $(\mathrm{cm})$ - median or more & $8 / 15$ & $1 / 1$ & $7 / 14(50 \%)$ \\
\hline Tumour gross picture (solid : mixed : cystic : not known) ${ }^{d}$ & $4: 9: 3: 1$ & $1 / 1$ & $3 / 15(20 \%)$ \\
\hline Lack of capsule & $3 / 17(17.6 \%)$ & $0 / 1$ & $13 / 16(81.25 \%)$ \\
\hline Incomplete capsule & $11 / 13(84.6 \%)$ & $1 / 1$ & $2 / 12(16.7 \%)$ \\
\hline Capsule invasion & $13 / 14(76.5 \%)$ & $1 / 1$ & $1 / 13(7.7 \%)$ \\
\hline Invasion of pancreatic parenchyma & $11 / 15(64.7 \%)$ & $1 / 1$ & $4 / 14(28.6 \%)$ \\
\hline Invasion of adipose tissue & $5 / 14(29.4 \%)$ & $0 / 1$ & $8 / 13(61.5 \%)$ \\
\hline Tumour at surgical margin & $3 / 11(17.6 \%)$ & $0 / 1$ & $7 / 10(70 \%)$ \\
\hline Perineural invasion & $9 / 17(52.9 \%)$ & $0 / 1$ & $7 / 16(43.75 \%)$ \\
\hline Small vessel invasion & $4 / 17(23.5 \%)$ & $0 / 1$ & $12 / 16(75 \%)$ \\
\hline Calcifications & $5 / 17(29.4 \%)$ & $0 / 1$ & $11 / 16(68.75 \%)$ \\
\hline Infarct necrosis & $6 / 17(35.3 \%)$ & $0 / 1$ & $10 / 16(62.5 \%)$ \\
\hline Geographical necrosis & $1 / 17(5.9 \%)$ & $0 / 1$ & $15 / 16(93.75 \%)$ \\
\hline Necrobiotic nests & $4 / 17(23.5 \%)$ & $0 / 1$ & $12 / 16(75 \%)$ \\
\hline Enlarged nuclei (more than $7.0 \mu \mathrm{m})^{\mathrm{e}}$ & $12 / 17(70.6 \%)$ & $1 / 1$ & $5 / 16(31.25 \%)$ \\
\hline Vesicular chromatin pattern (vs. fine chromatin) ${ }^{\mathrm{e}}$ & $8 / 17(47.1 \%)$ & $1 / 1$ & $9 / 16(56.25 \%)$ \\
\hline Enlarged nucleoli ${ }^{\mathrm{e}}$ & $7 / 17(41.2 \%)$ & $1 / 1$ & $10 / 16(62.5 \%)$ \\
\hline Nuclear atypia (moderate vs. minimal) ${ }^{\mathrm{e}}$ & $7 / 17(41.2 \%)$ & $1 / 1$ & $10 / 16(62.5 \%)$ \\
\hline Nuclear pleomorphism (minimal : moderate $:$ marked $)^{\mathrm{f}}$ & $7: 6: 4$ & $0 / 1$ & $12 / 16(75 \%)$ \\
\hline Multinucleated giant tumour cells & $7 / 17(41.2 \%)$ & $1 / 1$ & $10 / 16(62.5 \%)$ \\
\hline Nuclear grade $(1: 2: 3)^{\mathrm{e}}$ & $6: 5: 6$ & $1 / 1$ & $11 / 16(68.75 \%)$ \\
\hline $\begin{array}{l}\text { Solid-pseudopapillary carcinoma (WHO } 2000 \text { defini- } \\
\text { tion) }\end{array}$ & $14 / 17(82.4 \%)$ & $1 / 1$ & $3 / 16(18.75 \%)$ \\
\hline ENETS grade $(1: 2: 3)^{g}$ & $16: 1: 0$ & $0 / 1$ & $15 / 16(93.75 \%)$ \\
\hline ENETS T stage $(\mathrm{T} 1: \mathrm{T} 2: \mathrm{T} 3: \mathrm{T} 4: \mathrm{TX})^{\mathrm{h}}$ & $1: 4: 10: 0: 2$ & $1 / 1$ & $5 / 14(35.7 \%)$ \\
\hline AJCC T stage (pT1 : pT2 : pT3 : pT4: pTx) & $0: 9: 5: 0: 3$ & $0 / 1$ & $8 / 13(61.5 \%)$ \\
\hline Lymph node metastasis (pN0 : pN1 : pNx) & $10: 0: 7$ & - & - \\
\hline $\begin{array}{l}\text { Score according to the criteria of Nishihara et al. } \\
(1: 2: 3: 4: 5: 6: 7)\end{array}$ & $2: 1: 2: 5: 1: 3: 3$ & - & - \\
\hline $\begin{array}{l}\text { Score according to the criteria of Nishihara et al. - } \\
7 \text { or more }\end{array}$ & $3 / 17(17.6 \%)$ & $0 / 1$ & $13 / 16(81.25 \%)$ \\
\hline Clear cells & $16 / 17(94.1 \%)$ & $1 / 1$ & $1 / 16(6.25 \%)$ \\
\hline Spindle cells & $2 / 17(11.8 \%)$ & $0 / 1$ & $14 / 16(87.5 \%)$ \\
\hline Oncocytic cells & $4 / 17(23.5 \%)$ & $0 / 1$ & $12 / 16(75 \%)$ \\
\hline Eosinophilic globules & $13 / 17(76.5 \%)$ & $1 / 1$ & $4 / 16(25 \%)$ \\
\hline
\end{tabular}


Table I. Continue

\begin{tabular}{|c|c|c|c|}
\hline CHARACTERISTICS & Prevalence $(\mathrm{N}=17)$ & SENSITIVITY $^{\mathrm{b}}$ & SPECIFICITY $^{\mathrm{b}}$ \\
\hline Cholesterol clefts & $12 / 17(70.6 \%)$ & $1 / 1$ & $5 / 16(31.25 \%)$ \\
\hline Foamy cells & $17 / 17(100 \%)$ & $1 / 1$ & $0 / 16(0 \%)$ \\
\hline Microcystic growth pattern & $14 / 17(82.4 \%)$ & $1 / 1$ & $3 / 16(18.75 \%)$ \\
\hline Metachronous distant metastasis (pM1) & $1 / 17(5.9 \%)$ & - & - \\
\hline Clinically aggressive disease & $1 / 17(5.9 \%)$ & - & - \\
\hline \multicolumn{4}{|c|}{$\begin{array}{l}\text { a in some cases data were missing } \\
\text { b in identification of a clinically aggressive SPN } \\
\text { " localization of tumour in the pancreatic head was considered potential marker of an aggressive disease } \\
\text { d solid or mixed versus cystic architecture of the tumour was considered potential marker of an aggressive disease } \\
\text { a as proposed by Nishibara et al. } 499\} \\
\text { f marked versus minimal to moderate nuclear polymorphism of the tumour was considered potential marker of an aggressive disease } \\
\text { g ENETS grade } 2 \text { versus grade } 1 \text { was considered potential marker of an aggressive disease } \\
\text { b ENETS stage T3 versus ENETS stage T1 and T2 was considered potential marker of an aggressive disease } \\
\text { 'AJCC stage pT3 versus AJCC stage pT1 and pT2 was considered potential marker of an aggressive disease }\end{array}$} \\
\hline
\end{tabular}

ar features (size, chromatin pattern, nucleoli, atypia) and nuclear grade were described according to the definitions by Nishihara et al. [49]; (f) marked nuclear pleomorphism was recognized when variation of nuclear size was 4-fold or larger [7]; (g) ENETS tumour grade was assessed using criteria based on mitotic count and $\mathrm{Ki}-67$ proliferative index $[1,76]$; (h) SPC criteria were based on 2000 WHO publication [15]; (i) undifferentiated component was defined as area of diffuse growth pattern, tumour necrosis, nuclear atypia and 'unusually high' mitotic rate [33, 59]; (j) ENETS and AJCC tumour stage criteria were applied based on reference publications [76, 77]; and $(\mathrm{k})$ histopathological score was documented as proposed by Nishihara et al. [49]. Additionally, cases were examined also for presence of clear cells (vacuolization change) $[4,25,70,78,79]$, rhabdoid morphology [25], spindle cells $[80,81]$, oncocytic cells [14], eosinophilic (hyaline) globules [2], cholesterol clefts and foamy cells [2], as well as microcystic/ pseudoglandular growth pattern $[4,13,25,82]$.

The number of histological slides containing neoplastic tissue among study cases ranged from 2 to 12 (median 5). In 2 cases cytological smears were available. Both cases showed cytological features of SPN [83]. Some microscopic features of SPN are shown in Figure 1. Invasion of peripancreatic fat tissue was relatively frequent $(29.4 \%)$, but invasion of adjacent organs was not seen in any case. Lymph node metastases, invasion of muscular vessels, diffuse pattern of growth, rhabdoid cells and undifferentiated component were absent. The majority of cases showed features of SPC $(82.4 \%)$. The mitotic index did not exceed 1 mitotic figure per $2 \mathrm{~mm}^{2}$ in any of the cases. A single case showed a focal increase of $\mathrm{Ki}-67$ proliferative index up to $7 \%$ (ENETS tumour grade 2, assessed using the ImmunoRatio programme [84], Supplementary Fig. 3C). In all other cases, Ki-67 index was below $1 \%$. Clear cells were seen in all cases but one, but the proportion of that differentiation varied from case to case. Multinucleated tumour giant cells $[7,64]$ were seen in 7 cases $(41.2 \%)$. Tumours with multinucleated tumour cells were seen in significantly older patients than tumours with conventional cells only (median age 45 years and 34 years, respectively; Mann-Whitney U test, $\mathrm{p}=0.028$ ). Tumours with infarct-type necrosis were larger than those without such necrosis (median diameter $9 \mathrm{~cm}$ and $4 \mathrm{~cm}$, respectively; Mann-Whitney $\mathrm{U}$ test, $\mathrm{p}=0.024$ ).

\section{Follow-up}

Follow-up data were available for 14 patients and ranged from 7 to 246 months (median 52 months). A single patient developed liver metastasis (as described below). No case showed locoregional recurrence. All 14 patients were free of disease at the last follow-up.

\section{Clinically aggressive solid-pseudopapillary neoplasm}

A 45-year-old woman was treated with distal pancreatectomy due to a $7.8-\mathrm{cm}$ partially encapsulated tumour of the pancreatic tail. Neoplastic cells invaded the pancreatic parenchyma, and for that reason the tumour was diagnosed as SPC. Perineural and vascular invasion, infarct-type necrosis, and necrobiotic nests were absent. Focally, tumour cells were moderately atypical; multinucleated neoplastic cells were also found. The ENETS tumour grade was G1. The Nishihara score was 5. ENETS and AJCC tumour stages were $\mathrm{T} 3$ and $\mathrm{pT} 2$, respectively. The distance between tumour tissue and the surgical margin was $1 \mathrm{~mm}$. Following resection, the patient was treated with adjuvant chemotherapy but developed a solitary liver metastasis 17 months after pancreatic surgery. That $1.3 \mathrm{~cm}$ liver tumour was resected with a wide margin. Tumour cells in the metastatic lesion showed moderate cytological atypia. Multinucleated tumour cells and necrosis were absent. As in the primary tumour, hyaline globules were found. ENETS tumour grade was G1. At 29-months follow-up after resec- 
tion of metastatic deposit the patient remained well without signs of locoregional or distal recurrence.

\section{Immunohistochemical features}

Some results of IHC analysis are shown in Supplementary Fig. 3. All examined tumours (13/13) showed diffuse nuclear and cytoplasmic $\beta$-catenin staining. CD10 expression was seen in 11/12 cases and it was usually strong and diffuse (median histoscore 270). CD56 expression was found in 12/12 cases (median histoscore 225). PgR expression was seen in 12/12 cases - median percentage of positive nuclei was $90 \%$. Synaptophysin was expressed in $11 / 13$ cases, but in many cases it was weak and focal (median histoscore 50). Two cases showed 'positive' p53 immunostain: a $1.4 \mathrm{~cm}$-tumour in the pancreatic head of 42-year-old female (examined using conventional whole section) and a $10 \mathrm{~cm}$ tumour in pancreatic tail of 36-year-old female (examined using TMA). In the former case, strong p53 expression was seen in distinct portion of a tumour with many (degenerative) pleomorphic nuclei and multinucleated giant tumour cells, but it was not seen in other tumour areas. This was possibly caused by formation of subclone of tumoral cells with TP53 mutation, as proposed by other investigators [7]. In the latter case, p53 expression was also seen in pleomorphic nuclei. As in the previous study [7], expression of other IHC markers was similar in p53-positive and p53-negative cells. Claudin-5 expression was found in 10/12 cases. However, in 4 out of 10 positive cases it was only focal and/or weak, and histoscore in these cases ranged from 10 to 80 . The median histoscore among all evaluated cases was 100 (interquartile range 25-225). Results of IHC assays in a clinically aggressive tumour were very similar to benign SPN. The IHC profile of a liver metastasis in a single patient with clinically aggressive disease resembled the profile of the primary lesion.

\section{Clinicopathological features as predictors of clinically aggressive disease}

As presented in Table I, clinicopathological features did not show satisfactory diagnostic yield in identification of a clinically aggressive disease. In particular, many features previously recognized as useful for that purpose were seen in clinically benign cases.

\section{Discussion}

Solid-pseudopapillary neoplasm is a rare tumour. It develops almost exclusively in the pancreas, with the exception of extremely rare cases present in other areas/organs of the abdominal cavity $[40,41,85,86]$. The origin of SPN is still unknown [4], but its relation to stem cells of the pancreas [87], centroacinar cells $[80,88]$, genital ridge-related cells [78] or neural crest [89] was postulated. Recent gene expression studies provided new data on signalling pathways involved in SPN [89, 90]. An engineered mouse model of tumour compatible with SPN diagnosis is available [91].

Large series of patients with SPN treated in the USA, Europe and Asia are on record [5-7, 9, 10, $17-19,32,33,35,36,38,39,42,43,46,47,51$, 53-55, 59, 61, 64, 65-68, 71, 72-74, 75, 78, 92102]. In contrast, single case reports or series up to 6 cases have been described in Polish literature [103-111], including at least 3 cases with aggressive behavior $[105,108,109,111]$. Cumulative meta-synthetic reviews of clinicopathological features of SPN are also available $[20,56,65,74,75,87$, 102, 112-115].

The clinicopathological profile of SPN reported in the present series was similar to previous studies [4-6, 9, 17-19, 32, 33, 35, 36, 38, 39, 42, 43, 46, 47, 49, 51, 53-55, 59, 61, 64, 65-68, 71-74, 75, 78, 92-98, 100-102, 113, 116]. Majority of patients were young females. Tumours were relatively large and occurred in all segments of the pancreas.

Surgery is the only curative option for patients with SPN [16, 20, 21, 56, 60]. Resection of locally invasive tumour and metastases should be attempted whenever possible as it may result in long-term survival $[5,10,20,32,61,97,117]$. The 10-year survival rate in SPN is 94-96\% [5, 33]. It is not clear whether non-curative resection due to presence of neoplastic tissue at surgical margin is unfavourable prognostic factor in patients with SPN $[9,19,35,46$, 53, 54, 60, 99\}, but a recent study based on cumulative data suggests so [56]. Long-term survivals in patients with non-curative resections were described [9, 35, 68]. Long-term survival can also be obtained following metastasectomy [9, 32]. Spontaneous regression of primary SPN and liver metastases is even possible [118]. The role of radiotherapy and chemotherapy in SPN treatment is not well defined [16, 108, 119].

Histopathological features of SPN are well described $[1-4,22,25,120]$. Metastases of SPN usually resemble primary tumours morphologically $[48,57$, 61, 117].

The immunohistochemical profile of SPN is relatively specific [24]. SPN usually express $\beta$-catenin (nuclear stain), CD10, CD56, and PgR [24]. Claudin-5 was identified as a new marker of SPN, particularly useful in differential diagnosis of SPN and other 'solid cellular' neoplasms of the pancreas [26]. Comper et al. observed claudin-5 immunoexpression in all 20 SPN tested using conventional tissue sections [26]. We largely confirmed those observations, but $2 / 12$ of our cases were claudin- 5 negative and another 4 showed focal and/or weak staining. 

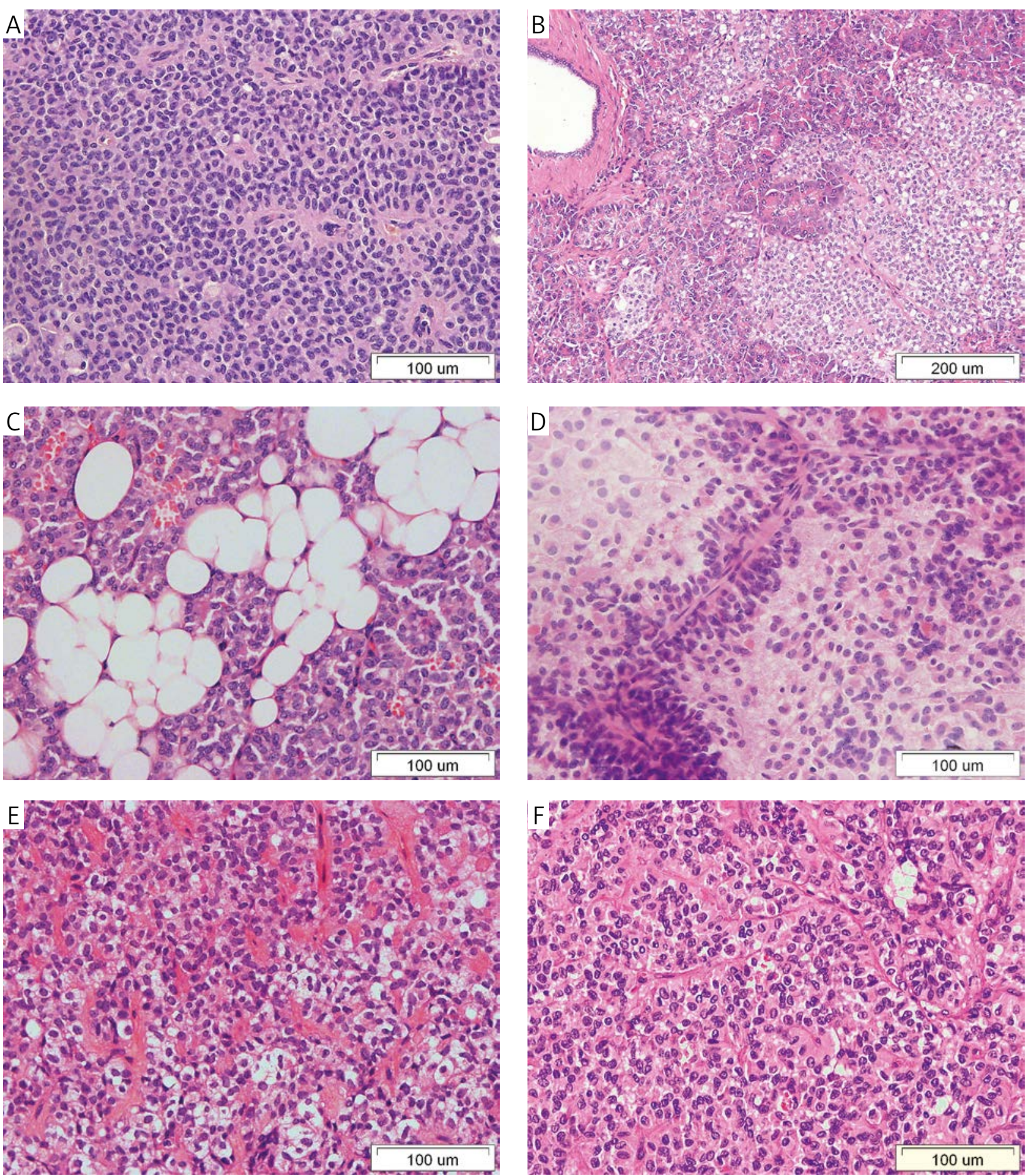

Fig. 1. Microscopical picture of SPN:

A) Solid growth pattern with delicate vessels; B) SPN and adjacent pancreatic parenchyma; C) Invasion of peripancreatic adipose tissue; D) Cytological picture of SPN; E) A clinically aggressive SPN - primary lesion; F) A clinically aggressive SPN - liver metastasis

This could be caused by differences in immunohistochemical protocols between studies, as well as usage of TMA in the present study. At present, lack of claudin-5 immunoexpression in a diagnostic sample does not exclude SPN diagnosis.

We noted a single clinically aggressive SPN in the present series $(5.9 \%)$. The percentage of cases with malignant features varies between studies, from less than $4 \%$ to more than $20 \%[5,19,33,35,38,49$, $53,85]$. This may be related to differences in criteria of malignancy, follow-up protocols, adjuvant treatment, as well as patients' characteristics.

Despite systematic evaluation of large number of histopathological features, we were unable to identify 
both sensitive and specific risk factors of aggressive behaviour of SPN. Similar observations have been made by other investigators $[9,16,21,33]$. Importantly, aggressive behaviour may appear many years after potentially curative tumour resection [117]. At present, locoregional or distant recurrence of SPN after tumour resection is unpredictable [21].

According to other reports, SPC diagnosis is a sensitive but not specific risk factor for clinically aggressive disease $[18,19,43,66,67]$. The percentage of SPC in the present study was $82.4 \%$, and it was high in comparison to previous reports. The percentage of SPC among SPN varied significantly between studies (from $8.2 \%$ up to $70 \%$ ) $[18,19,32,42,43,53,65,66-68$, $94,97]$. This may be related to differences between patient populations and possibly to somewhat imprecise criterion of SPC diagnosis [15]. "Deep invasion [of tumour] into the surrounding tissue" [15] may be interpreted as invasion of pancreatic parenchyma or invasion of peripancreatic adipose tissue, or invasion of adjacent organs. In the present series invasion of peritumoral pancreatic parenchyma was sufficient for the diagnosis of SPC. Restriction of that criterion to cases showing invasion of peripancreatic tissues resulted in lower percentage of SPC among SPN cases (64.7\%).

p53 immunoexpression is rare but possible in SPN [11]. It may be associated with presence of pleomorphic nuclei and it usually correlates with TP53 mutation [7]. Pleomorphic nuclei and atypical multinucleated giant tumour cells possibly represent senescence-related tumour degeneration rather than true atypia [7, 64]. Pleomorphism is not associated with increased mitotic count, increased $\mathrm{Ki}-67$ proliferative index, or importantly, with clinically aggressive behaviour $[7$, 64]. In the present series, 2 cases showed p53 immunoexpression in areas which were composed, but not exclusively, of cells with pleomorphic nuclei.

The Ki-67 proliferative index in conventional SPN ranges from 0 to $10 \%$ [57, 121-123]. Ki-67 expression may correlate to some extent with 'malignancy' or local invasion of SPN [20, 57, 71, 93, 116]. In some reports, $\mathrm{Ki}-67$ expression was documented only in cases with invasion of pancreatic parenchyma [93, 116]. Ki-67 indices in SPN and SPC are similar $[53,123]$. We observed a single SPN with a slightly increased Ki-67 index. During 90-month follow-up, that patient did not have a recurrence. Distant metastases of SPN usually retain low Ki-67 indices [45, 48]. We did not observe an increase of Ki-67 expression in liver metastasis in comparison to the primary tumour.

Some groups have suggested that there were some differences in IHC profile between clinically benign and malignant SPN. For example, the extent of CD56 stain may be slightly higher in SPN with synchronous liver metastases than in SPN without metastases during presentation [124]. In another study, synaptophysin was seen in a single metastasizing tumor but not in 6 SPN without metastases [122]. We did not confirm these observations. Other investigators found differences in IHC pattern between primary and secondary deposits of SPN. Geers et al. observed weak/negative CD10, CD56, galectin-3 and PR staining in liver metastasis of SPN [70]. In other report, primary SPN and metachronous liver metastasis showed focally positive and negative CD10 staining, respectively [22]. Like another group [57], we did not find differences in results of IHC between pancreatic tumour and distant metastasis.

Results of molecular studies also did not allow identification of a highly specific genomic profile of aggressive SPN [125, 126]. Aneuploidy seems to be a feature of invasive and/or metastasizing SPN, and SPN in males [49, 62, 127], but these features may not be sensitive and specific enough [122].

In very rare cases, SPN may progress to an undifferentiated neoplasm of extreme clinical aggressiveness [33]. This may happen at the stage of primary tumour $[33,58,59]$ or metastatic deposits $[41$, $82,127]$. Diffuse growth pattern, significant atypia, extensive necrosis, high mitotic index and high Ki-67 proliferative index are features of undifferentiated neoplasm derived from SPN [33, 41, 58, 59, $82,127]$. A high-grade tumour component may lose expression of some classical SPN markers (CD10, CD56) and gain expression of epithelial (EMA, Cam 5.2) or even melanocytic (HMB-45) markers [33, 58]. We did not observed undifferentiated SPN in the present series.

The limitation of our study is the relatively small number of examined cases, especially in comparison with recent large series from Asia [7, 19, 32, 38, 47].

\section{Conclusions}

In the present study we systematically evaluated a large number of histopathological features of SPN. At present, histopathological examination cannot identify patients who may develop locoregional or distant tumour recurrence following resection of a primary tumour. For that reason, a close follow-up should be offered to all patients treated for SPN.

\section{Acknowledgements}

We are grateful to Piotr Konicki, MSc, Elżbieta Kowal, MSc, and Grażyna Boba, MSc for performing immunohistochemical stains, and to Dariusz Gołka, $\mathrm{MD} \mathrm{PhD}$ for language editing of the manuscript.

\section{Note}

During the peer review of the manuscript we encountered another case of a clinically aggressive SPN. 
Metastatic foci of SPN were found in several samples of peritoneal and peripancreatic tissues taken from a 38-year-old woman who underwent a distal pancreatectomy 20 years earlier at outside our institution. Secondary SPN deposits (slides of the primary lesion were not available for review) showed enlarged nuclei and nucleoli, moderate pleomorphism, scattered multinucleated giant cells and necrobiotic nests, and rare mitotic figures. Nuclear grade was 2, ENETS grade was 1 , and Nishihara score was 7 . The IHC profile was typical for SPN.

The authors declare no conflict of interests.

This study was supported by internal institutional grant of Medical University of Silesia, Katowice, Poland.

\section{References}

1. Kloppel G, Hruban RH, Klimstra DS, et al. Solid-pseudopapillary neoplasm of the pancreas. In: WHO classification of tumours of the digestive system. Bosman FT, Carneiro F, Hruban RH, Theise ND (eds.) 4th ed. IARC, Lyon 2010; 327-330.

2. Hruban RH, Pitman M, Klimstra DS. Tumors of the pancreas. Series 4. AFIP, Washington 2007.

3. Campbell F, Verbeke CS. Pathology of the pancreas. A practical approach. Springer, London 2013.

4. Klimstra DS, Wenig BM, Heffess CS. Solid-pseudopapillary tumor of the pancreas: a typically cystic carcinoma of low malignant potential. Semin Diagn Pathol 2000; 17: 66-80.

5. Estrella JS, Li L, Rashid A, et al. Solid pseudopapillary neoplasm of the pancreas. Clinicopathologic and survival analyses of 64 cases from a single institution. Am J Surg Pathol 2014; 38: $147-157$.

6. Valsangkar NP, Morales-Oyarvide V, Thayer SP, et al. 851 resected cystic tumors of the pancreas: a 33-year experience at the Massachusetts General Hospital. Surgery 2012; 3 (Suppl. 1): S4-S12.

7. Kim SA, Kim MS, Kim MS, et al. Pleomorphic solid pseudopapillary neoplasm of the pancreas: degenerative change rather than high-grade malignant potential. Hum Pathol 2014; 45: 166-174.

8. Kloppel G, Solcia E, Longnecker DS, et al. Histological typing of tumours of the exocrine pancreas. Springer, Berlin 1996.

9. Reddy S, Cameron JL, Scudiere J, et al. Surgical management of solid-pseudopapillary neoplasms of the pancreas (Frantz or Hamoudi tumors): a large single-institutional series. J Am Coll Surg 2009; 208; 950-959.

10. Tipton SG, Smyrk TC, Sarr MG, et al. Malignant potential of solid pseudopapillary neoplasm of the pancreas. Br J Surg 2006; 93: 733-737.

11. Abraham SC, Klimstra DS, Wilentz RE, et al. Solid-pseudopapillary tumors of the pancreas are genetically distinct from pancreatic ductal adenocarcinomas and almost always harbor $\beta$-catenin mutations. Am J Pathol 2002; 160: 1361-1369.

12. Wu J, Jiao Y, Dal Molin M, et al. Whole-exome sequencing of neoplastic cysts of the pancreas reveals recurrent mutation in components of ubiquitin-dependent pathways. Proc Natl Acad Sci U S A 2011; 108: 21188-21193.

13. Frantz VK. Tumors of the pancreas. Atlas of tumor pathology. Fascicles 27 and 28. AFIP, Washington, 1959, F27-32.

14. Hamoudi AB, Misugi K, Grosfeld JL, et al. Papillary epithelial neoplasm of pancreas in a child. Report of a case with electron microscopy. Cancer 1970; 26: 1126-1130.
15. Kloppel, G, Luttges J, Klimstra DS, et al. Solid-pseudopapillary neoplasm. In: Pathology and genetics of tumours of the digestive system. Hamilton SR, Aaltonen LA (eds.) 3rd ed. IARC, Lyon 2000; 246-248.

16. Del Chiaro M, Verbeke C, Salvia R, et al. European experts consensus statement on cystic tumours of the pancreas. Dig Liver Dis 2013; 45: 703-711.

17. Ansari D, Elebro J, Tingstedt B, Ygland E, et al. Single-institution experience with solid pseudopapillary neoplasm of the pancreas. Scand J Gastroenterol 2011; 46: 1492-1497.

18. El Nakeeb A, Abdel Wahab M, Elkashef WF, et al. Solid pseudopapillary tumour of the pancreas: incidence, prognosis and outcome of surgery (single center experience). Int J Surg 2013; 11: 447-457.

19. Kim CW, Han DJ, Kim J, et al. Solid pseudopapillary tumor of the pancreas: can malignancy be predicted? Surgery 2011; 149: 625-634.

20. Papavramidis T, Papavramidis S. Solid pseudopapillary tumors of the pancreas: review of 718 patients reported in English literature. J Am Coll Surg 2005; 200: 965-972.

21. Reddy S, Wolfgang CL. Solid pseudopapillary neoplasms of the pancreas. Adv Surg 2009; 43: 269-282.

22. Notohara K, Hamazaki S, Tsukayama C, et al. Solid-pseudopapillary tumor of the pancreas. Immunohistochemical localization of neuroendocrine markers and CD10. Am J Surg Pathol 2000; 24: 1361-1371.

23. Ilyas M, Grabsch $\mathrm{H}$, Ellis $\mathrm{O}$, et al. Guidelines and considerations for constructing experiments using tissue microarrays. Histopathology 2013; 62: 827-839.

24. Serra S, Chetty R. Revision 2: an immunohistochemical approach and evaluation of solid pseudopapillary tumour of the pancreas. J Clin Pathol 2008; 61: 1153-1159.

25. Notohara K, Wani Y, Fujisawa M. Solid pseudopapillary neoplasm: pathological diagnosis and distinction from other cellular tumours of the pancreas. Diagn Histopathol 2008; 14: 266-274.

26. Comper F, Antonello D, Beghelli S, et al. Expression pattern of claudins 5 and 7 distinguishes solid-pseudopapillary from pancteatoblastoma, acinar cell and endocrine tumors of the pancreas. Am J Surg Pathol 2009; 33: 768-774.

27. Stamos JL, Weis WI. The $\beta$-catenin destruction complex. In: Wnt signaling. Nusse R, He X, van Amerongen R (eds.), Cold Spring Harbor, New York 2013; 89-104.

28. Barker N, van dern Born M. Detection of $\beta$-catenin localization in immunohistochemistry. In: Wnt signaling. Vincan $\mathrm{E}$ (ed.), Humana Press, New York 2010; 91-98.

29. Yemelyanova A, Vang R, Kshirsagar M, et al. Immunohistochemical staining patterns of $\mathrm{p} 53$ can serve as a surrogate marker for TP53 mutations in ovarian carcinoma: an immunohistochemical and nucleotide sequencing analysis. Mod Pathol 2011; 24: 1248-1253.

30. Numata M, Morinaga S, Watanabe T, et al. The clinical significance of SWI/SNF complex in pancreatic cancer. Int J Oncol 2013; 42: 403-410.

31. GENE-E. Url: http://www.broadinstitute.org/cancer/software/ GENE-E/index.html Assessed November 2013.

32. Park JK, Cho EJ, Ryu JK, et al. Natural history and malignant risk factors of solid pseudopapillary tumors of the pancreas. Postgrad Med 2013; 125: 92-99.

33. Tang LH, Aydin H, Brennan MF, et al. Clinically aggressive solid pseudopapillary tumors of the pancreas. Am J Surg Pathol 2005; 29: 512-519.

34. Takahashi H, Hashimoto K, Hayakawa H, et al. Solid cystic tumor of the pancreas in elderly men: report of a case. Surg Today 1999; 29: 1264-1267.

35. Butte JM, Brennan MF, Gonen M, et al. Solid pseudopapillary tumors of the pancreas. Clinical features surgical outcomes, and long-term survival in 45 consecutive patients from a single center. J Gastrointest Surg 2011; 15: 350-357. 
36. Li Z, Zhang Z, Liu X, et al. Solid pseudopapillary tumor of the pancreas: the surgical procedures. Surg Today 2011; 41: 91-96.

37. Gou S, Yu J, Wang C, et al. Three female familial cases of solid pseudopapillary tumors with a protease serine 1 gene mutation. Pancreas 2013; 42: 168-173.

38. Wang LJ, Bai L, Su D, et al. Retrospective analysis of 102 cases of solid pseudopapillary neoplasm of the pancreas in China. J Int Med Res 2013; 41: 1266-1271.

39. Guo Y, Yuan F, Deng H, et al. Paranuclear dot-like immunostaining for CD99: a unique staining pattern for diagnosing solid-pseudopapillary neoplasm of the pancreas. Am J Surg Pathol 2011; 35: 799-806.

40. Zhu H, Xia D, Wang B, et al. Extrapancreatic solid pseudopapillary neoplasm: report of a case of primary retroperitoneal origin and review of the literature. Oncol Lett 2013; 5: 150-1504

41. Hibi T, Ojima H, Sakamoto Y, et al. A solid pseudopapillary tumor arising for the greater omentum followed by multiple metastases with increasing malignant potential. J Gastroenterol 2006; 41: 276-281.

42. Yin Q, Wang M, Wang C, et al. Differentiation between benign and malignant solid pseudopapillary tumor of the pancreas by MDCT. Eur J Radiol 2012; 81: 3010-3018.

43. Kim HH, Yun SK, Kim JC, et al. Clinical features and surgical outcome of solid pseudopapillary tumor of the pancreas: 30 consecutive clinical cases. Hepato-gastroenterology 2011; 58: 1002-1008.

44. Stommer P, Kraus J, Stolte M, et al. Solid and cystic pancreatic tumors. Clinical, histochemical, and electron microscopic features in ten cases. Cancer 1991; 67: 1635-1641.

45. Tajima Y, Kohara N, Maeda J, et al. Peritoneal and nodal recurrence 7 years after the excision of a ruptured solid pseudopapillary neoplasm of the pancreas: report of a case. Surg Today 2012; 42: 776-780.

46. Nguyen NQ, Johns AL, Gill AJ, et al. Clinical and immunohistochemical features of 34 solid pseudopapillary tumours of the pancreas. J Gastroenterol Hepatol 2011; 26: 267-274.

47. Ye J, Ma M, Cheng D, et al. Solid-pseudopapillary tumor of the pancreas: clinical features, pathological characteristics, and origin. J Surg Oncol 2012; 106: 728-735.

48. Muller-Hocker J, Zietz Ch, Sendelhofert A. Deregulated expression of cell-cycle-associated proteins in solid pseudopapillary tumor of the pancreas. Mod Pathol 2001; 14: 47-53.

49. Nishihara K, Nagoshi M, Tsuneyoshi M, et al. Papillary cystic tumors of the pancreas. Assessment of their malignant potential. Cancer 1993; 71: 82-92.

50. A-Cienfuegos J, Lozano MD, Rotellar F, et al. Solid pseudopapillary tumor of the pancreas (SPPT). Still an unsolved enigma. Rev Esp Enferm Dig 2010; 102: 722-728.

51. Cai H, Zhou M, Hu Y, et al. Solid-pseudopapillary neoplasms of the pancreas: clinical and pathological features of 33 cases. Surg Today 2013; 43: 148-154.

52. Vassos N, Agaimy A, Klein P, et al. Solid-pseudopapillary neoplasm (SPN) of the pancreas: case series and literature review on an enigmatic entity. Int J Clin Exp Pathol 2013; 6: 1051-1059.

53. Morikawa T, Onogawa T, Maeda S, et al. Solid pseudopapillary neoplasms of the pancreas: an 18-year experience at a single Japanese Institution. Surg Today 2013; 43: 26-32.

54. Guo N, Zhou QB, Chen RF, et al. Diagnosis and surgical treatment of solid pseudopapillary neoplasm of the pancreas: analysis of 24 cases. Can J Surg 2011; 54: 368-374.

55. Kang CM, Choi SH, Hwang HK, et al. Minimally invasive (laparoscopic and robot-assisted) approach for solid pseudopapillary tumor of the pancreas: a single-center experience. J Hepatobiliary Pancreat Sci 2011; 18: 87-93.

56. Campanile M, Nicolas A, LeBel S, et al. Frantz's tumor: is mutilating surgery always justified in young patients? Surg Oncol 2011; 20: 121-125.
57. Takahashi Y, Fukusato T, Aita K, et al. Solid pseudopapillary tumor of the pancreas with metastases to the lung and liver. Pathol Int 2005; 55: 792-796.

58. Adamthwaite JA, Verbeke CS, Stringer MD, et al. Solid pseudopapillary tumour of the pancreas: diverse presentation, outcome and histology. JOP J Pancreas 2006; 7: 635-642.

59. Martin RC, Klimstra DS, Brennan MF, et al. Solid-pseudopapillary tumor of the pancreas: a surgical enigma? Ann Surg Oncol 2002; 9: 35-40.

60. Kang CM, Hwang HK, Kim H, et al. Marginally calcified totally necrotic tumor of the pancreas. Pancreas 2013; 42: 184-186.

61. Huang SC, Ng KF, Yeh TS, et al. Clinicopathological analysis of $\beta$-catenin and Axin- 1 in solid pseudopapillary neoplasms of the pancreas. Ann Surg Oncol 2012; 19 (suppl. 3): S438-S446.

62. Cho NH, Go JH, Jung SH, et al. Correlation between proliferating index and prognostic factors in papillary cystic tumors of the pancreas. J Korean Med Sci 1995; 10: 342-351.

63. Treglia G, Caporale N, Rufini V, et al. Usefulness of ${ }^{18} \mathrm{~F}-\mathrm{FDG}$ PET/CT in an unusual case of solid-pseudopapillary pancreatic tumor in childhood with aggressive behavior. Clin Nucl Med 2013; 38: e35-e37.

64. Li L, Othman M, Rashid A, et al. Solid pseudopapillary neoplasm of the pancreas with prominent atypical multinucleated giant tumour cells. Histopathology 2013; 62: 465-471.

65. Yoon WJ, Lee JK, Lee KH, et al. Cystic neoplasms of the exocrine pancreas. An update of a nationwide survey in Korea. Pancreas 2008; 37: 254-258.

66. Lee SE, Jang JY, Hwang DW, et al. Clinical features and outcome of solid pseudopapillary neoplasm. Differences between adults and children. Arch Surg 2008; 143: 1218-1221.

67. Yu CC, Tseng JH, Yeh CN, et al. Clinicopathological study of solid pseudopapillary tumor of pancreas: emphasis on magnetic resonance imaging findings. World J Gastroenterol 2007; 13: 1811-1815.

68. Goh BK, Tan YM, Cheow PC, et al. Solid pseudopapillary neoplasms of the pancreas: an updated experience. J Surg Oncol 2007; 95: 640-644.

69. Nishihara K, Tsuneyoshi M. Papillary cystic tumours of the pancreas: an analysis by nuclear morphometry. Virchows Arch 1993; 422: 211-217.

70. Geers C, Moulin P, Gigot JF, et al. Solid and pseudopapillary tumor of the pancreas - review and new insight into pathogenesis. Am J Surg Pathol 2006; 30: 1243-1249.

71. Yang F, Jin C, Long J, et al. Solid pseudopapillary tumor of the pancreas: a case series of 26 consecutive patients. Am J Surg 2009; 198: 210-215.

72. Machado MC, Machado MA, Bacchella T, et al. Solid pseudopapillary neoplasm of the pancreas: distinct patterns of onset, diagnosis, and prognosis for male versus female patients. Surgery 2008; 143: 29-34.

73. Kang CM, Kim KS, Choi JS, et al. Solid pseudopapillary tumor of the pancreas suggesting malignant potential. Pancreas 2006; 32: 276-280.

74. Lin MY, Stabile BE. Solid pseudopapillary neoplasm of the pancreas: a rare and atypically disease among male patients. Am Surg 2010; 76: 1075-1078.

75. Tien YW, Ser KH, Hu RH, et al. Solid pseudopapillary neoplasms of the pancreas: is there a pathologic basis for the observed gender differences in incidence? Surgery 2005; 137 : 591-596.

76. Rindi G, Kloppel G, Alhman H, et al. TNM staging of foregut (neuro)endocrine tumors: a consensus proposal including a grading system. Virchows Arch 2006; 449: 395-401.

77. Edge SB, Byrd DR, Compton CC, et al. AJCC cancer staging manual. Seventh edition. American Joint Committee on cancer, Springer, New York 2010. 
78. Kosmahl M, Seada LS, Janig U, et al. Solid-pseudopapillary tumor of the pancreas: its origin revisited. Virchows Arch 2000; 436: 473-480.

79. Albores-Saavedra J, Simpson KW, Bilello SJ. The clear cell variant of solid pseudopapillary tumor of the pancreas: a previously unrecognized pancreatic neoplasm. Am J Surg Pathol 2006; 30: 1237-1242.

80. Bergmann F, Andrulis M, Hartwig W, et al. Discovered on gastrointestinal stromal tumor 1 (DOG1) is expressed in pancreatic centroacinar cells and in solid-pseudopapillary neoplasms - novel evidence for a histogenetic relationship. Hum Pathol 2011; 42: 817-823.

81. El-Bahrawy MA, Khorsandy S, Williamson R, et al. Spindle cell solid pseudopapillary tumor of the pancreas. A newly described variant. Pancreas 2010; 39: 255-257.

82. Matsunou H, Konishi F. Papillary-cystic neoplasm of the pancreas. A clinicopathologic study concerning the tumor aging and malignancy of nine cases. Cancer 1990; 65: 283-291.

83. Samad A, Shah AA, Stelow EB, et al. Cercariform cells: another cytologic feature distinguishing solid pseudopapillary neoplasms form pancreatic endocrine neoplasms and acinar cell carcinomas in endoscopic ultrasound-guided fine-needle aspirates. Cancer Cytopathol 2013; 121: 398-310.

84. Tuominen VJ, Ruotoistenmaki S, Viitanen A, et al. ImmunoRatio: a publicly available web application for quantitative image analysis of estrogen receptor (ER), progesterone receptor (PR), and Ki-67. Breast Cancer Res 2010; 12: R56.

85. Yang F, Fu D, Jin C, et al. Clinical experiences of solid pseudopapillary tumors of the pancreas in China. J Gastroenterol Hepatol 2008; 23: 1847-1851.

86. Deshpande V, Oliva E, Young RH. Solid pseudopapillary neoplasm of the ovary: a report of 3 primary ovarian tumors resembling those of the pancreas. Am J Surg Pathol 2010; 34 1514-1520.

87. Mao C, Guvendi M, Domenico DR, et al. Papillary cystic and solid tumors of the pancreas: a pancreatic embryonic tumor? Studies of three cases and cumulative review of the world's literature. Surgery 1995; 118: 921-828.

88. Kallichanda N, Tsai S, Stabile BE, et al. Histogenesis of solid pseudopapillary tumor of the pancreas: the case for the centroacinar cell of origin. Exp Mol Pathol 2006; 81: 101-107.

89. Cavard C, Audebourg A, Letourneur F, et al. Gene expression profiling provides insights into pathways involved in solid pseudopapillary neoplasm of the pancreas. J Pathol 2009; 218: 201-209.

90. Park M, Kim M, Hwang D, et al. Characterization of gene expression and activated signaling pathways in solid-pseudopapillary neoplasm of the pancreas. Mod Pathol 2014, 27: 580-593.

91. Heiser PW, Cano DA, Landsman L, et al. Stabilization of $\beta$-catenin induces pancreas tumor formation. Gastroenterology 2008 ; $135: 1288-1300$.

92. Matos JM, Grutzmann R, Agaram NP, et al. Solid pseudopapillary neoplasms of the pancreas: a multi-institutional study of 21 patients. J Surg Res 2009; 157: e137-e142.

93. Wang XG, Ni QF, Fei JG, et al. Clinicopathologic features and surgical outcome of solid pseudopapillary tumor of the pancreas: analysis of 17 cases. World J Surg Oncol 2013; 11: 38.

94. Chung YE, Kim MJ, Choi JY, et al. Differentiation of benign and malignant solid pseudopapillary neoplasms of the pancreas. J Comput Assist Tomogr 2009; 33: 689-694.

95. Hu S, Huang W, Lin X, et al. Solid pseudopapillary tumour of the pancreas: distinct patterns of computed tomography manifestation for male versus female patients. Radiol Med 2014, 119: 83-89.

96. Raman SP, Kawamoto S, Law JK, et al. Institutional experience with solid pseudopapillary neoplasms: focus on computed tomography, magnetic resonance imaging, conventional ultrasound, endoscopic ultrasound, and predictors of aggressive histology. J Comput Assist Tomogr 2013; 37: 824-833.

97. Cheng K, Shen B, Peng C, et al. Synchronous portal-superior mesenteric vein or adjacent organ resection for solid pseudopapillary neoplasms of the pancreas: a single-institution experience. Am Surg 2013; 79: 534-539.

98. Zhang RC, Yan JF, Xu XW, et al. Laparoscopic vs. open distal pancreatectomy for solid pseudopapillary tumor of the pancreas. World J Gastroenterol 2013; 19: 6272-6277.

99. van den Akker M, Angelini P, Taylor G, et al. Malignant pancreatic tumors in children: a single-institution series. J Pediatr Surg 2012; 47: 681-687.

100. Salvia R, Bassi C, Festa L, et al. Clinical and biological behavior of pancreatic solid pseudopapillary tumors: report on 31 consecutive patients. J Surg Oncol 2007; 95: 304-310.

101. Cai Y, Ran X, Xie S, et al. Surgical management and longterm follow-up of solid pseudopapillary tumor of pancreas: a large series form a single institution. J Gastrointest Surg 2014 , in press.

102. Manuballa V, Amin M, Cappell MS. Clinical presentation and comparison of surgical outcome for segmental resection vs. Whipple's procedure for solid pseudopapillary tumor: report of six new cases and literature review of 321 cases. Pancreatology 2014, 14: 71-80.

103. Burdan F, Mocarska A, Guz E, et al. Solid-psuedopapillary neoplasm of the pancreas - comparison between magnetic resonance and histological findings. Pol J Pathol 2013; 64: 216-223.

104. Korlacki W, Dzielicki J, Grabowski A. Laparoscopic distal pancreatectomy in children with solid pseudopapillary tumour (Frantz tumour) - a report of two cases and review of the literature. Videosurgery Miniinv 2010; 5: 65-69.

105. Cichocki A, Nawrocki G, Roszkowska-Purska K, et al. Single center experience in the treatment if solid pseudopapillary neoplasms of the pancreas. J Oncol 2011; 61: 126-129.

106. Piekarek A, Mańkowski P, Sosnowski P. Solid-pseudopapillary tumor of the pancreas in a 13-year-old girl - case report. Pol J Radiol 2008; 73: 67-69.

107. Pisanko A, Gałązka P, Chrupek M, et al. Solid-pseudopapillary tumor of the pancreas in children - a plea for saving the spleen. Ann Diagn Paediatr Pathol 2008; 12: 81-85.

108. Murawa D, Zasadowski Z, Kruszyna $~ Z$. A second relapse of a solid pseudopapillary tumor of the pancreas: case description. Pol J Surg 2008; 80: 46-50.

109. Łaggiewska B, Pacholczyk M, Lisik W, et al. Liver transplantaion for nonresectable metastatic solid pseudopapillary pancreatic cancer. Ann Transplant 2013; 18: 651-653.

110. Wideł M, Kryj M, Półtorak S. Papillary-cystic neoplasm of the pancreas - a case report. J Oncol 2001; 51: 390-392.

111. Stachura J, Popieta T, Pietroń M, et al. Cytology of solid and papillary epithelial neoplasms of the pancreas: a case report. Diagn Cytopathol 1988; 4: 339-341.

112. Yu PF, Hu ZH, Wang XB, et al. Solid pseudopapillary tumor of the pancreas: a review of 553 cases in Chinese literature. World J Gastroenterol 2010; 16: 1209-1214.

113. Hao CY, Lu AP, Xing BC, et al. Solid pseudopapillary tumor of the pancreas: report of 8 cases in a single institution and review of the Chinese literature. Pancreatology 2006; 6: 291-296.

114. Sclafani LM, Reuter VE, Coit DG, et al. The malignant nature of papillary and cystic neoplasm of the pancreas. Cancer 1991; 68: 153-158

115. Yang F, Fu D, Jin C, et al. Clinical experiences of solid pseudopapillary tumors of the pancreas in China. J Gastroenterol Hepatol 2008; 23: 1847-1851.

116. Yu P, Cheng X, Guo J, et al. Solid pseudopapillary tumor of the pancreas: clinical analysis of 11 cases. Hepato-gastroenterology 2011; 58: 192-197. 
117. Gomez P, Yorke R, Ayala AG, et al. Solid-pseudopapillary neoplasm of pancreas with long delayed liver metastasis. Ann Diagn Pathol 2012; 16: 380-384.

118. Yoon HJ, Lim JH. Solid pseudopapillary tumor of the pancreas with hepatic metastasis: spontaneous regression over 10year follow-up period. Korean J Radiol 2012; 13: 648-651.

119. Ji S, Xu J, Zhang B, et al. Management of a malignant case of solid pseudopapillary tumor of pancreas. A case report and literature review. Pancreas 2012; 41: 1336-1340.

120. Kim MJ, Jang SJ, Yu E. Loss of E-cadherin and cytoplasmic-nuclear expression of $\beta$-catenin are the most useful immunoprofiles in the diagnosis of solid-pseudopapillary neoplasm of the pancreas. Hum Pathol 2008; 39: 251-258.

121. Kang CM, Kim HK, Kim H, et al. Cyclooxigenase-2 (COX-2) expression in solid pseudopapillary tumor of the pancreas. A pilot study. Pancreas 2011; 40: 159-160.

122. Lai HW, Su CH, Fen-Yau A, et al. Malignant solid and pseudopapillary tumor of the pancreas - clinicohistological, immunohistochemical, and flow cytometric evaluation. Hepato-gastroenterology 2006; 53: 291-295.

123. Kang CM, Kim HK, Kim H, et al. Expression of Wnt target genes in solid pseudopapillary tumor of the pancreas. Pancreas 2009; 38: e53-e59.

124. Serra S, Salahshor S, Fagih M, et al. Nuclear expression of E-cadherin in solid pseudopapillary tumors of the pancreas. JOP J Pancreas 2007; 8: 296-303.

125. Rund CR, Moser AJ, Lee KK, et al. Array comparative genomic hybridization analysis of solid pseudopapillary neoplasms of the pancreas. Mod Pathol 2008; 21: 559-564.

126. Morita K, Urushihara N, Fukumoto K, et al. Solid pseudopapillary tumor of the pancreas in children: surgical intervention strategies based on pathological findings. Pediatr Surg Int 2014, 30: 253-257.

127. Cappellari JO, Geisinger KR, Albertson DA, et al. Malignant papillary cystic tumor of the pancreas. Cancer 1990; 66: 193-198.

\section{Address for correspondence}

\section{Lukasz Liszka MD}

Department of Pathomorphology in Katowice

Medical University of Silesia

Medyków 18

40-754 Katowice, Poland

tel./fax +4832 2525080

e-mail: lliszka@mp.pl 